\title{
BIOGEOGRAPHY OF THE CRETACEOUS / TERTIARY PLANKTIC FORAMINIFERAL FAUNAL TRANSITION
}

MACLEOD, Norman, Dept. of Geological and Geophysical Sciences, Princeton

University, Princeton, NJ 08544, U.S.A.; KELLER*, Gerta, Dept. of Geological and Geophysical Sciences, Princeton University, Princeton, NJ 08544 U.S.A.

Quantitative analysis of a high resolution latest Maastrichtian through Danian planktic foraminiferal database reveals that degrees of endemism characterizing tropical Tethyan and both northern and southern high latitude faunas throughout this interval are much lower than previously supposed. In terms of temporal patterns in the relative abundance of cosmopolitan species, the transition from the diverse globotruncaniddominated late Maastrichtian assemblage (I), characterizing the lower portion of the $A$. mayaroensis / P. deformis zones prior to the base of Chron 29, to the diverse globigerinid-dominated Danian assemblage (V) found in Zone P1c and above, takes place through the successive rise and fall of at least three intermediate faunal associations. These include: a mixed assemblage (II) that delineates an interval from the base of Chron 29 to lowermost Danian Zone PO and is dominated by heterohelicids, hedbergellids, and globigerinelloids; a guembelitrid-dominated assemblage (III) that ranges through lower Danian zones PO - P1a; and a chiloguembelinid-dominated assemblage (IV) that characterizes lower Danian zones P1a through P1b.

Species whose differential relative abundances identify them as more or less endemic to a northern high latitude biogeographic province include Guembelitria danica (assemblage III), Chiloguembelitria waiparensis (assemblage IV), and Eoglobigerina danica (assemblage V), while southern high latitude forms with endemic abundance acmes include $C$. waiparensis (assemblage III) and several globigerine species (e.g., Globigerina extensa, Igorina spiralis, Globigerina aequiensis, Globigerina chasconoma). Tropical tethyan abundance endemics include Heterohelix navarroensis and Pseudoguembelina costulata (fauna II), along with both Parvularugoglobigerina eugubina and Woodringina hornerstownensis (assemblage IV). Overall, levels of planktic foraminiferal endemism were quite low throughout the upper Maastrichtian $A$. mayaroensis / $P$. deformis zones, across the K/T boundary, and into the Danian Zone P0. Endemism increased gradually throughout zones P1a and P1b with the addition of species to both northern high latitude and tropical tethyan biogeographic provinces, and then increased much more substantially in Zone P1c with the addition of the southern high latitude globigerine species.

Our analysis has also uncovered several instances of dramatic abundance increases for individual taxa occurring significantly earlier in the southern high latitudes (e.g., Chiloguembelina waiparensis). Associated with these diachronous relative abundance patterns, stable isotopic studies indicate that environmental conditions (e.g., temperature, organic productivity) over this $\mathrm{K} / \mathrm{T}$ transition interval were more stable in the southern ocean than in tropics. Finally, our data reveals a distinct difference and mirror-image ordering in both the disappearance and successive reappearance of the planktic foraminiferal test morphotypes (e.g., keeled trochospires, globigerine trochospires, forms with serially arranged chambers) that prevailed in each faunal assemblage. We believe that these data can best be accounted for by accepting a causal model of geographically heterogeneous deterioration and subsequent restructuring of marine planktic habitats that took place over an extended interval of time and was ultimately driven by a synergistic combination of climatic (global cooling), oceanographic (sea level change) and tectonic factors. 